\title{
VANDALISME KOLEKSI DI PERPUSTAKAAN SMA NEGERI 8 PEKANBARU
}

\author{
Citra Ayu Kinanti \\ Program Studi Ilmu Perpustakaan, Fakultas Ilmu Budaya, Universitas Lancang Kuning \\ E-mail : citraayu2799@gmail.com \\ Rosman \\ Program Studi Ilmu Perpustakaan, Fakultas Ilmu Budaya, Universitas Lancang Kuning \\ E-mail: rosman20@unilak.ac.id

\section{Rismayeti} \\ Program Studi Ilmu Perpustakaan, Fakultas Ilmu Budaya, Universitas Lancang Kuning \\ E-mail: rismayeti@gmail.com
}

Received: 09-06-2021

Revised: 15-06-2021

Accepted:23-06-2021

DOI: 10.24036/ib.v2i2.178

\section{Abstract}

This study aims to determine how the collection vandalime acts that occur in the library of SMA Negeri 8 Pekanbaru. The research method used is quantitative methods, with data collection techniques through observation, interviews, literature study and documentation. The research sample was 99 books. The results showed that vandalism to cross certain pages was the most prevalent vandalism, amounting to $38.26 \%$. Then the page folding vandalism was $26.95 \%$. Hacking vandalism on certain pages $24.35 \%$. Book vandalism that is not returned, vandalism marking sentences with $4.35 \%$ coloring. Vandalism wrote a book margin of $1.74 \%$. Vandalism in the type of image cutting, page cutting, etc. was not found in vandalism, so the percentage was $0 \%$.

Keywords: Collection; High School Library; Vandalism

\section{Abstrak}

Penelitian ini bertujuan untuk mengetahui bagaimana tindakan vandalime koleksi yang terjadi di perpustakaan SMA Negeri 8 Pekanbaru. Metode penelitian yang digunakan adalah metode kuantitatif, dengan teknik pengumpulan data melalui observasi, wawancara, studi pustaka dan dokumentasi. Sampel penelitian berjumlah 99 Eksemplar buku. Hasil penelitian menunjukan bahwa vandalisme mencoret halaman tertentu merupakan vandalisme yang paling banyak terjadi yaitu sebanyak 38,26\%. Kemudian vandalisme pelipatan halaman 26,95 \%. Vandalisme perobekan pada halaman tertentu 24,35\%. Vandalisme buku yang tidak dikembalikan, vandalisme penandaan kalimat dengan perwarna 4,35 \%. Vandalisme menulis poin margin buku 1,74\%. Vandalisme jenis pengguntingan gambar, pengeratan halaman, dll tidak ditemukan tindakan vandalisme, sehingga persentasenya $0 \%$.

Kata Kunci: Koleksi; Perpustakaan SMA; Vandalisme 


\section{PENDAHULUAN}

Adanya perpustakaan disekolah bukan hanya untuk mengumpulkan dan menyimpan bahan-bahan pustaka, tetapi penyelenggaraan perpustakaan sekolah diharapkan dapat membantu siswa dan guru menyelesaikan tugastugas dalam proses belajar mengajar. Didalam sebuah perpustakaan sudah pasti terdapat koleksi. Koleksi menurut (Prastowo, 2012, hal. 116) adalah "Sekumpulan bahan pustaka, baik yang berbentuk buku maupun non-buku, yang dikelola sedemikian rupa oleh suatu perpustakaan (sekolah) untuk turut serta menjamin kelancaran dan keberhasilan kegiatan proses pembelajaran disekolah". Didalam koleksi buku-buku itulah yang menjadi sumber informasi dalam perpustakaan. Koleksi juga berguna untuk menunjang kegiatan belajar mengajar. Mengingat beragamnya sifat dan perilaku siswa juga guru dalam mencari informasi diperpustakaan, maka buku-buku (koleksi tercetak) yang ada diperpustakaan itu pun akan rawan terkena kerusakan. Untuk menghindari itu, perpustakaan memberikan aturanaturan yang disertai sanksi yang tegas didalam perpustakaan. Akan tetapi pustakawan di Perpustakaan SMA Negeri 8 Pekanbaru kurang tegas akan pemberian sanksi kepada pelanggarnya di dalam perpustakaan ini. Bukti dari kejadian itu ditandai dengan banyaknya bahan pustaka yang rusak akibat dari pemustaka yang melanggar peraturan tersebut. Untuk faktor yang dapat merusak koleksi perputakaan yaitu bisa dari faktor alam dan juga faktor manusia. Perilaku ini tentunya dapat merugikan diri sendiri, perpustakaan, dan juga para pemustaka lain, karena informasi yang diinginkan tidak tersampaikan dengan jelas dan lengkap.

Perpustakaan SMAN 8 Pekanbaru merupakan salah satu tempat penyedia informasi bagi siswa hingga staf pengajar yang ada disekolah tersebut. Disini juga tidak terlepas dari adanya tindakan vandalisme baik itu dari siswa, staf pengajar maupun pustakawannya. Jika dilihat dari hasil observasi di lapangan terdapat beberapa koleksi buku yang robek, kemudian hilangnya halaman buku, 
terpisahnya buku dari cover, terlambatnya pengembalian buku, melipat-lipat lembaran buku, dan mencoret buku. Tindakan seperti ini sangat tidak boleh dilakukan karena akan membuat para pemustaka/siswa lain yang ingin mencari informasi menjadi tidak mendapatkan informasi yang diinginkan. Maka dengan melihat kejadian seperti ini perlu diadakannya penelitian lebih dalam mengenai Vandalisme. Terutama jika dilihat dari jenis kelamin, umur dan perbedaan emosi disetiap siswa SMA yang berbeda-beda. Menurut (Fagan, 2006) "Tingkatan Psikologis di setiap siswa SMA yang berkisar diusia 15 sampai 18 tahun ini menjadi salah satu faktor terjadinya penyalahgunaan koleksi atau Vandalisme. Karena pada usia 15 sampai 18 tahun, para siswa akan mengalami masa transisi (masa perubahan) dari remaja menuju dewasa, dimana emosi siswa masih belum stabil dan cendrung lebih aktif dalam segala hal. Dalam usia ini siswa akan lebih tertarik dengan hal-hal fiksi karena akan menambah juga memperluas pemahaman terhadap apa- apa saja yang mungkin dan tidak mungkin terjadi". Maka dari itu para siswa lebih menyukai buku-buku fiksi untuk memenuhi informasinya tersebut.

Karena hal itulah penulis akan melakukan penelitian mengenai vandalisme untuk melihat seberapa jauh siswa SMA Negeri 8 Pekanbaru bisa menghargai buku dengan tingkat emosi yang masih belum stabil itu. Penelitan ini berjudul "Vandalisme Koleksi Di Perpustakaan SMA Negeri 8 Pekanbaru".

\section{TINJAUAN TEORITIS}

1. Perpustakaan Sekolah

Dalam Undang-undang Republik Indonesia nomor, 43 tahun 2007 tentang perpustakaan menyebutkan bahwa: "Perpustakaan adalah institusi pengelolaan koleksi karya tulis, karya cetak, atau karya rekam secara professional dengan sistem yang baku guna memenuhi kebutuhan pendidikan, penelitian, pelestarian, informasi, dan 


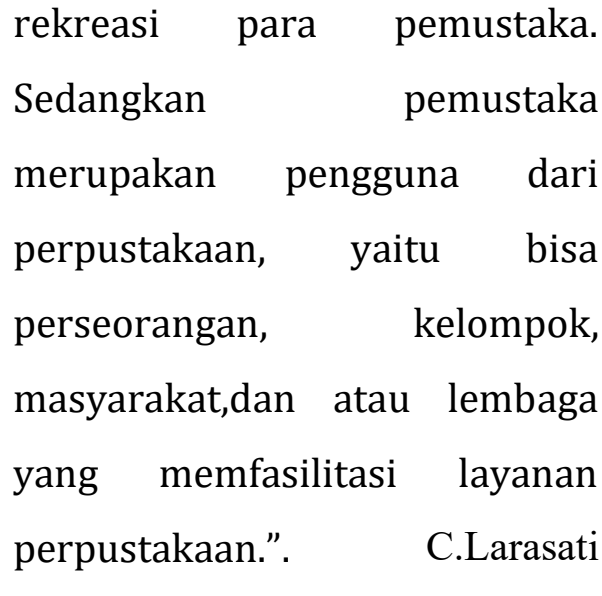

Milburga dalam (Masturi, 2011, hal. 10) mengatakan bahwa "Perpustakaan sekolah ialah suatu unit kerja dari sebuah lembaga persekolahan yang berupa tepat penyimpanan koleksi bahan pustaka penunjang proses pendidikan, yang diatur secara sistematis, untuk digunakan secara berkesinambungan sebagai sumber informasi untuk perkembangan dan memperdalam pengetahuan, baik oleh pendidik maupun yang dididik di sekolah tersebut". Dapat disimpulkan pengertian perpustakaan sekolah yaitu perpustakaan yang didirikan oleh sekolah, dan berada dilingkungan sekolah, yang kemudian menjadi sarana penunjang disekolah, dengan tujuan utamanya untuk membantu tercapainya tujuan pendidikan yang diselengarakan oleh sekolah, dimana perpustakaan sekolah itu berada.

2. Vandalisme Vandalisme merupakan perusakan atau penyalahgunaan barang milik umum. Menurut Kamus Besar Bahasa Indonesia istilah Vandalisme secara umum adalah 1. Perbuatan merusak dan menghancurkan hasil karya seni dan barang berharga lainnya, 2. Penghancuran dan perusakan secara kasar. Pertambahan koleksi diperpustakaan haruslah diimbangi dengan ditambahnya alat pengaman untuk koleksi dalam perpustakaan. Lain dari itu berbagai peraturan yang perpustakaan terapkan haruslah dilaksanakan sebaik-baiknya, agar bisa memperkecil tindakan menyimpang dari pemustaka. 
Published by Program Studi Perpustakaan dan Ilmu Informasi FBS Universitas Negeri Padang, Indonesia

Contoh dari tindakan menyimpang yang terjadi yaitu menyalah gunakan koleksi perpustakaan seperti pencurian, tindakan ini akan berakibat pada kurangnya koleksi di

3. Vandalisme Koleksi

Vandalisme pada koleksi tercetak perpustakaan adalah "kerusakan pada koleksi perpustakaan, perabot atau fasilitas perpustakaan yang dilakukan dengan sengaja, biasanya dimotivasi oleh kemarahan atau kebencian dari pelaku". Bentuk vandalisme koleksi tercetak yang terjadi didalam perpustakaan seperti mencoret atau menulis kalimat penting pada kerts buku, kemudian memberi tanda menggunakan stabillo, catatan dibagian samping kalimat, menulis argumen pada sisi margin kalimat atau kutipan tertentu. Hal lain yang yang bisa mendatangkan masalah di perpustakaan ialah sengaja menggambar yang tidak perpustakaan. Hal ini juga dapat merugikan pihak perpustakaan dan pemustaka bahkan diri sendiri. Tindakan menyimpang ini sudah termasuk tindakan Vandalisme.

memiliki arti, menekuk halaman buku guna sebagai penanda halaman bacaan, sengaja merobek halaman khusus, hilangnya ilustrasi atau gambar, terdapat robekan pada grafik data. Dan yang paling fatal adalah hilangnya buku dari perpustakaan secara sengaja oleh pemustaka. Semua kegiatan tersebut dapat memunculkan masalah serius pada perpustakaan. Perpustakaan harus berupaya meningkatkan pengawasan serta pengamanan untuk koleksinya, contohnya bisa dengan dirumuskannya kebijakan keamanan yang komperhensif seperti, sistem keamanan yang diintegrasi dalam fasilitas desain perpustakaan contohnya 
Published by Program Studi Perpustakaan dan Ilmu Informasi FBS Universitas Negeri Padang, Indonesia

dengan memperhatikan

penempatan tata letak koleksi perpustakaan, tata letak furnitur yang tidak menghalangi pandangan, atau dengan diadakannya petugas pengontrol yang berkeliling.

\section{METODE}

Penelitian dilakukan pada Perpustakaan SMA Negeri 8 Pekanbaru, mulai dari bulan Juli 2020 sampai dengan bulan April 2021. Populasi penelitian sebanyak 19.404 eksemplar buku dari keseluruhan koleksi tercetak di Perpustakaan SMA Negeri 8 Pekanbaru dan sampel yang diambil sebanyak 99 eksemplar buku dari populasi. Metode yang digunakan dalam penelitian ini adalah metode kuantitatif dengan teknik pengumpulan data melalui observasi lapangan, wawancara, studi pustaka, dan dokumentasi. Pada penelitian ini menggunakan variabel tunggal yaitu "Vandalisme Koleksi di Perpustakaan", dengan indikator sebagai berikut:
Tabel 1. Variabel Vandalisme

Sumber : Fatmawati (Daryono, 2014) dan Isaac Olugbenga (Rahmawati, 2014).

\begin{tabular}{|c|c|}
\hline Variabel & Indikator \\
\hline $\begin{array}{l}\text { Vandalisme } \\
\text { Koleksi di } \\
\text { Perpustakaan }\end{array}$ & $\begin{array}{l}\text { 1. Coret-mencoret } \\
\text { halaman tertentu } \\
2 . \quad \text { Pelipatan halaman } \\
\text { tertentu } \\
\text { 3. Pengguntingan } \\
\text { gambar-gambar tertentu } \\
\text { 4. Pengeratan dan } \\
\text { pembetotan halaman } \\
5 . \quad \text { Perobekan pada } \\
\text { halaman tertentu } \\
\text { 6. Memanfaatkan kartu } \\
\text { anggota perpustakaan milik } \\
\text { orang lain } \\
\text { 7. Buku yang tidak } \\
\text { dikembalikan } \\
\text { 8. Penjiplakan/plagiat } \\
\text { karya ilmiah } \\
9 . \quad \text { Mutilasi dan } \\
\text { pencurian buku koleksi } \\
\text { perpustakaan } \\
\text { 10. Menandai kalimat } \\
\text { dengan pena berwarna } \\
\text { 11. Menuliskan poin } \\
\text { pada margin buku }\end{array}$ \\
\hline
\end{tabular}

\section{HASIL DAN PEMBAHASAN}

Untuk mendapatkan jawaban dari rumusan masalah penelitian ini maka 
penulis melakukan observasi lapangan dan juga mewawancarai kepala perpustakaan, pustakawan dan beberapa pemustaka. Wawancara dilakukan tanggal 24 September 2020 15 April 2021. Para informan tersebut adalah orang-orang yang terlibat langsung dalam pemanfaatan juga pengelolaan perpustakaan. Berikut adalah tabel dari bentuk vandalisme yang ada di Perpustakaan SMA Negeri 8 Pekanbaru:

Tabel 2. Jenis Vandalisme yang diteliti pada perpustakaan

\begin{tabular}{|c|c|c|c|}
\hline No. & Jenis Vandalisme & Frekuensi & $\begin{array}{c}\text { Persentase } \\
(\%)\end{array}$ \\
\hline 1. & $\begin{array}{l}\text { Coret-mencoret } \\
\text { halaman tertentu }\end{array}$ & 44 koleksi & $38,26 \%$ \\
\hline 2. & $\begin{array}{l}\text { Pelipatan halaman } \\
\text { tertentu }\end{array}$ & 31 koleksi & $26,95 \%$ \\
\hline 3. & $\begin{array}{l}\text { Pengguntingan } \\
\text { gambar-gambar } \\
\text { tertentu }\end{array}$ & 0 Koleksi & $0 \%$ \\
\hline 4. & $\begin{array}{l}\text { Pengeratan dan } \\
\text { pembetotan } \\
\text { halaman }\end{array}$ & 0 Koleksi & $0 \%$ \\
\hline 5. & $\begin{array}{l}\text { Perobekan pada } \\
\text { halaman tertentu }\end{array}$ & 28 Koleksi & $24,35 \%$ \\
\hline 6. & $\begin{array}{l}\text { Memanfaatkan } \\
\text { kartu anggota } \\
\text { perpustakaan milik }\end{array}$ & 0 Koleksi & $0 \%$ \\
\hline
\end{tabular}

\begin{tabular}{|c|l|c|c|}
\hline 7. & $\begin{array}{l}\text { orang lain } \\
\text { dikembalikan }\end{array}$ & 5 Koleksi & $4,35 \%$ \\
\hline 8. & $\begin{array}{l}\text { Penjiplakan/plagiat } \\
\text { karya ilmiah }\end{array}$ & 0 Koleksi & $0 \%$ \\
\hline 9. & $\begin{array}{l}\text { Mutilasi dan } \\
\text { pencurian buku } \\
\text { koleksi } \\
\text { perpustakaan }\end{array}$ & 0 Koleksi & $0 \%$ \\
\hline 10. & $\begin{array}{l}\text { Menandai kalimat } \\
\text { dengan pewarna }\end{array}$ & 5 Koleksi & $4,35 \%$ \\
\hline 11. & $\begin{array}{l}\text { Menuliskan poin } \\
\text { pada margin buku }\end{array}$ & $\begin{array}{l}\text { 2 Koleksi } \\
\text { Jumlah }\end{array}$ & $1,74 \%$ \\
\hline
\end{tabular}

Tabel di atas menunjukkan bahwa hanya terdapat 6 indikator vandalisme yang terjadi di perpustakaan SMA Negeri 8 Pekanbaru. Dapat diketahui hampir setengah atau sebanyak 44 koleksi dengan persentase $38,26 \%$ coret-mencoret halaman tertentu, 31 koleksi dengan persentase $26,95 \%$ pelipatan halaman tertentu, 28 koleksi dengan persentase 24,35\% perobekan pada halaman tertentu, dan sebagian kecil atau 5 koleksi dengan persentase $4,35 \%$ buku yang tidak dikembalikan, 5 koleksi dengan persentase $4,35 \%$ menandai kalimat dengan pena berwarna, 2 koleksi 
dengan persentase 1,74\% menuliskan poin pada margin buku, 0 koleksi dengan persentase $0 \%$ pengguntingan gambar-gambar tertentu, 0 koleksi dengan persentase $0 \%$ memanfaatkan kartu anggota milik orang lain, 0 koleksi dengan persentase $0 \%$ penjiplakan/plagiat karya ilmiah, 0 koleksi dengan persentase $0 \%$ mutilasi dan pencurian buku koleksi perpustakaan. Selanjutnya penulis akan menjabarkan masing-masing jenis vandalisme yang terjadi di SMA Negeri 8 Pekanbaru, seperti berikut:

\section{Coret-Mencoret}

Halaman

\section{Tertentu}

Mencoret-coret buku merupakan salah satu vandalisme yang paling banyak terjadi dalam perpustakaan. Hampir setengah dari 99 sampel buku yang diambil terjadi vandalisme yang dengan bentuk coret-mencoret ini. Coretmencoret terjadi oleh alat tulis seperti pensil, pewarna, spidol, ballpoint, stabillo, dan lain-lain. Dari hasil wawancara dengan Kepala Perpustakaan, pustakawan, dan pemustaka di SMA Negeri 8 Pekanbaru didapatilah simpulan hasil dari wawancara tersebut bahwa didalam Perpustakaan SMA Negeri 8 Pekanbaru belum ada peraturan tertulis secara formal tentang larangan vandalisme. Tetapi pihak perpustakaan sudah selalu menghimbau para pemustaka agar tidak melakukan tindakan yang akan merusak koleksi perpustakaan. Walaupun sudah diberi himbauan seperti itu, vandalisme ini masih saja dilakukan oleh pemustaka. Dan belum ada sanksi yang jelas untuk tindakan tersebut.

\section{Pelipatan Halaman Tertentu}

Pelipatan pada halaman tertentu merupakan jenis vandalisme yang ditemui hampir disetiap koleksi perpustakaan. Vandalisme jenis pelipatan halaman tertentu ini walaupun sudah diluruskan kembali tetapi tetap akan meninggalkan jejak atau bekas lipatannya, yang lambat launnya akan menyebabkan kertas menjadi lapuk kemudian robek. Kemudian Penulis melakukan wawancara kepada beberapa informan. Dari wawancara tersebut didapatilah simpulan hasil wawancara bahwa vandalisme jenis pelipatan halaman 
tertentu dapat terjadi karena para pemustaka ingin menandai bahan bacaannya yang dianggap penting juga bacaan yang kemudian akan ia baca kembali. Tetapi akibat dari pelipatan ini akan membuat kertas pada halaman buku tersebut akan lapuk dan mudah robek nantinya. Beberapa dari pemustaka lain juga tidak setuju dengan hal ini, karena masih banyak benda lain yang dapat digunakan sebagai pembatas (penanda) buku.

\section{Pengguntingan}

Gambar-

\section{Gambar Tertentu}

Pengguntingan gambar-gambar tertentu merupakan suatu tindakan yang sangat fatal bagi penyebaran informasi dalam perpustakaan, yaitu dimana pelaku dengan sengaja menggunting gambar-gambar yang menurutnya menarik menggunakan alat pemotong, kemudian menyimpan nya ataupun dibuang. Kejadian ini biasanya terjadi pada buku yang memiliki gambar-gambar menarik. Tetapi dalam perpustakaan ini tidak ditemukan vandalisme penggunting gambar-gambar tertentu pada bahan pustakanya. Dari hasil wawancara dengan Kepala Perpustakaan, pustakawan, dan pemustaka di SMA Negeri 8 Pekanbaru didapatilah simpulan hasil dari wawancara tersebut bahwa vandalisme dengan jenis pengguntigan gambar-gambar tertentu ini belum pernah terjadi, begitu juga ketika penulis melakukan penelitian ini. Penulis tidak menemukan adanya vandalisme jenis ini yang terjadi di Perpustakaan SMA Negeri 8 Pekanbaru.

\section{Pengeratan Dan Pembentotan}

\section{Halaman}

Pengeratan ataupun pembentotan memiliki makna yang sama. Tindakan ini terjadi karena suatu tindakan yang disengaja oleh pemustaka. Bentuk dari tindakan pengeratan dan pembentotan ini yaitu seperti dengan sengaja mencabut halaman tertentu dan kemudian mengakibatkan isi dari buku tersebut tidak tersusun sesuai dengan urutannya semula. Setelahnya akan berujung pada penyebaran informasi buku yang tidak lengkap. Dari hasil wawancara dengan Kepala Perpustakaan, pustakawan, dan pemustaka di SMA Negeri 8 Pekanbaru 
Published by Program Studi Perpustakaan dan Ilmu Informasi

didapatilah simpulan hasil wawancara tersebut bahwa jarang ditemukannya vandalisme jenis pembentotan dan pengereratan di Perpustakaan ini, dan jika pun ada pihak perpustakaan akan langsung memperbaiki bahan pustaka tersebut sesuai dengan kerusakannya.

\section{Perobekan Pada Halaman}

\section{Tertentu}

Perobekan pada halaman tertentu merupakan tindakan tercela yang sengaja dilakukan demi kepuasan diri sendiri tetapi akan merugikan orang lain pula. Karena kegiatan perobekan ini akan menyebabkan hilangnya informasi dari bahan pustaka tersebut. Dari hasil wawancara dengan Kepala Perpustakaan, pustakawan, dan pemustaka di SMA Negeri 8 Pekanbaru didapatilah simpulan hasil dari wawancara tersebut bahwa vandalisme dengan jenis perobekan ini masih terus terjadi didalam Perpustakaan SMA Negeri 8 Pekanbaru, dan dengan sigap pula dari pihak perpustakaan melakukan perbaikan dan juga penyiangan untuk buku dengan kondisi yang sudah tidak baik lagi.

\section{Memanfaatkan Kartu Anggota} Perpustakaan Milik Orang Lain

Memanfaatkan kartu anggota perpustakaan milik orang lain merupakan suatu tindakan yang menyalahi aturan perpustakaan, dimana tindakan ini termasuk kedalam vandalisme. Salah satu faktor yang mempengaruhi tejadinya hal ini yaitu karena pemustaka lupa untuk membawa kartu anggota. Tetapi di Perpustakaan SMA Negeri 8 Pekanbaru tidak ditemukan adanya vandalisme dengan jenis memanfaatkan kartu anggota perpustakaan milik orang lain. penulis melakukan wawancara dengan beberapa informan, dari hasil wawancara didapatilah simpulan bahwa vandalisme memanfaatkan kartu anggota perpustakaan milik orang lain tidak terjadi di Perpustakaan SMA Negeri 8 Pekanbaru karena siswa dan juga tenaga pengajar sudah termasuk kedalam anggota perpustakaan tersebut.

\section{Buku Yang Tidak \\ Dikembalikan}

Buku yang tidak dikembalikan ini merupakan suatu kejahatan yang akan 
sangat merugikan perpustakaan.

Karena salah satu bahan pustaka yang dipinjam tidak dikembalikan lagi dan sudah bisa dikategorikan sebagai bahan pustaka yang hilang. Setelah melakukan penelitian langsung di Perpustakaan SMA Negeri 8 Pekanbaru penulis melakukan wawancara. Dari hasil wawancara dengan Kepala Perpustakaan, pustakawan, dan pemustaka di SMA Negeri 8 Pekanbaru didapatilah simpulan hasil dari wawancara tersebut bahwa jika bahan perpustakaan yang dipinjam tidak dikembalikan dalam jangka waktu yang ditentukan, maka pustakawan akan memberikan teguran kepada pemustaka tersebut. Dan apabila pemustaka tadi tidak menghiraukan teguran yang diberikan pustakawan maka pustakawan akan memberikan sanksi kepada pemustaka. Pustakawan juga memberikan pilihan bagi pemustaka yang tidak mengembalikan buku dengan memberikan buku yang serupa ataupun dengan judul yang memiliki makna sama.

\section{Penjiplakan/Plagiat Karya Ilmiah}

Penjiplakan atau plagiat karya ilmiah juga termasuk salah satu jenis vandalisme didalam perpustakaan. Yang dimaksud dari penjiplakan/ plagiarisme ini adalah suatu tindakan mencuri karangan milik orang lain, kemudian meniru tulisan orang lain dan mengakui hasil tulisan tersebut sebagai hasil karangan sendiri. Salah satu hal yang menyebabkan terjadinya vandalisme jenis plagiat pada karya ilmiah didalam perpustakaan yaitu karena rendahnya minat baca pemustaka, serta kurangnya pemahaman juga latihan untuk menulis karya ilmiah. Kemudian penulis mewawancarai kepala perpustakaan, pustakawan, dan pemustaka di SMA Negeri 8 Pekanbaru. Dari hasil wawancara tersebut didapatilah simpulan bahwa vandalisme dengan jenis plagiat karya ilmiah ini tidak pernah terjadi di perpustakaan SMA Negeri 8 Pekanbaru. Karena disetiap penulisan karya ilmiah oleh siswa sudah dibimbing langsung oleh guru yang bersangkutan. 


\section{Mutilasi Dan Pencurian Buku} Koleksi Perpustakaan

Mutilasi merupakan suatu kejadian dimana kondisi halaman pada buku sudah tidak lengkap lagi. Hal ini dikarenakan halaman tersebut sudah sengaja dirobek, sehingga informasi yang terkandung didalam buku tidak lengkap lagi. Tentu saja tindakan ini akan menyebabkan biaya preservasi yang tinggi bagi perpustakaan. Dan juga pastinya kebiasaan buruk ini akan bisa menularkan kepada orang lain. Kemudian pencurian buku, yang dimaksud dengan pencurian buku disini yaitu suatu tindakan mengambil bahan pustaka tanpa melalui prosedur yang berlaku atau tanpa sepengetahuan pihak perpustakaan. Dari hasil wawancara dengan Kepala Perpustakaan, pustakawan, dan pemustaka di SMA Negeri 8 Pekanbaru didapatilah simpulan hasil dari wawancara tersebut bahwa tidak terdapat buku yang dimutilasi dan juga pencurian terhadap buku, dikarenakan siswa-siswa SMA Negeri 8 Pekanbaru selalu diajarkan untuk berlaku jujur dalam setiap tindakan, dan juga pustakawan yang selalu mengontrol perlakuan dari pemustakanya selama didalam perpustakaan menggunakan CCTV yang ada dipojok perpustakaan. Hal ini juga sudah dibuktikan oleh penulis dengan penelitian secara langsung ke Perpustakaan SMA Negeri 8 Pekanbaru.

\section{Menandai Kalimat Dengan}

\section{Pena Berwarna}

Vandalisme dengan menggunakan pena berwarna sebagai alat penanda bacaan pada buku sudah termasuk kedalam jenis kejahatan terhadap koleksi perpustakan. Karena penandaan dengan menggunakan pena berwarna sudah merusak karya milik orang lain. Dan lebih fatalnya lagi akan merusak informasi didalam buku tersebut. Dari hasil wawancara dengan Kepala Perpustakaan, pustakawan, dan pemustaka di SMA Negeri 8 Pekanbaru didapatilah simpulan hasil dari wawancara tersebut bahwa didalam Perpustakaan hanya sedikit terjadinya pencoretan dengan menggunakan pena berwarna, dan pihak pemustaka juga dengan cepat bertindak menghapus segala coretan yang bisa dihapus agar 
Published by Program Studi Perpustakaan dan Ilmu Informasi

informasi dibuku tidak tertutupi atau hilang. Hal ini tentunya sudah dilihat dan dicek langsung oleh penulis di Perpustakaan SMA Negeri 8 Pekanbaru.

\section{Menuliskan Poin Pada Margin} Buku

Menuliskan poin pada margin buku sama halnya dengan merusak hasil karya milik orang lain. Dimana pemustaka menuliskan poin-point yang dianggapnya penting pada bagian tepi buku. Hal tersebut tentunya dapat menghilangkan sisi keindahan dari karya seseorang. Dari hasil wawancara dengan Kepala Perpustakaan, pustakawan, dan pemustaka di SMA Negeri 8 Pekanbaru didapatilah simpulan hasil dari wawancara tersebut bahwa vandalisme jenis penulisan poin pada margin buku ini sangat jarang terjadi di Perpustakaan SMA Negeri 8 Pekanbaru, karena biasanya para pemustaka atau siswa jarang ada yang mau menulis kembali poin dari buku tersebut, justru penandaan poin terjadi dengan menggaris bawahi tulisan dari buku itu sendiri.

\section{PENUTUP}

\section{Simpulan}

Berdasarkan dari hasil penelitian yang telah dilakukan oleh penulis, maka dapat diperoleh simpulan bahwa Vandalisme yang paling sering terjadi di Perpustakaan SMA Negeri 8 Pekanbaru adalah jenis Vandalisme coret - mencoret halaman tertentu sebanyak 38,26\% yang berarti hampir setengah dari 99 sampel terjadi tindakan Vandalisme tersebut, selain itu jenis Vandalisme yang juga terjadi adalah Pelipatan halaman tertentu yang berjumlah 26,95\%, Perobekan pada halaman tertentu sebanyak 24,35\%, Buku yang tidak dikembalikan sebanyak 4,35\%, Menuliskan poin pada margin buku 1,74\%, serta jenis Vandalisme Menandai kalimat dengan pena berwarna sebanyak 4,35\%. Sedangkan untuk jenis Vandalisme Pengguntingan gambar-gambar tertentu, Pengeratan dan pembetotan halaman, Memanfaatkan kartu anggota perpustakaan milik orang lain, Penjiplakan/plagiat karya ilmiah, 
Mutilasi dan pencurian buku koleksi perpustakaan tidak ditemukan di $\begin{array}{llll}\text { Perpustakaan } & \text { SMA Negeri } 8\end{array}$ Pekanbaru dengan persentase sebesar $0 \%$.

\section{Saran}

a. Perlu adanya Sanksi yang lebih tegas oleh pustakwan terhadap pelanggaran didalam perpustakaan

b. Pengecekan kembali perlu diadakan ketika pengembalian bahan pustaka oleh pemustaka di perpustakaan.

c. Perlu adanya pemeriksaan terhadap CCTV Perpustakaan secara berkala

d. Perlu di adakannya sosialisasi terhadap tata tertib di Perpustakaan SMA Negeri 8 Pekanbaru.

\section{DAFTAR PUSTAKA}

Bafadal, I. (2009). Pengelolaan Perpustakaan Sekolah. Jakarta: Bumi Aksara.

Daryono. (2014). Perilaku Vandalisme Pemustaka Di Pusat Perpustakaan Universitas Islam Negeri (UIN) Syarif Hidayatullah Jakarta. Journal UIN Syarif Hidayatullah Jakarta , 24.

Elnadi, I. (2018). Vandalisme Koleksi di Unit Pelayanan Teknis (UPT) Perpustakaan Universitas Bengkulu. Jurnal Ilmu Perpustakaan dan Informasi STAIN Curup, II, 43.
Fagan. (2006). Psikologi Remaja. Jakarta: PT.Gramedia.

Fitriany, J. (2016). Vandalisme Di Perpustakaan Soeman Hs. Pekanbaru: Universitas Lancang Kuning.

Gustiyani, S. (2020). Vandalisme Pada Perpustakaan SD Negeri 86 dan SMP Negeri 6 di Kecamatan Rumbai Pesisir Pekanbaru. Pekanbaru: Universitas Lancang Kuning.

Masturi, M. H. (2011). Pengaruh Pemanfaatan Perpustakaan Sekolah . UIN Syarif Hidayatullah, 9.

Prastowo, A. (2012). Manajemen Perpustakaan Sekolah Profesional. Yogyakarta: DIVAPress.

Rahmawati, G. N. (2014). Perilaku Vandalisme Pemustaka di Pusat Perpustakaan UIN Syarif Hidayatullah. UIN SSyarif Hidayatullah, 23.

Sevilla, G. (1993). Pengantar Metode Penelitian. Jakarta: UI-PRESS.

Sugiyono. (2016). Metode Penelitian Kualitatif, Kuantitatif, dan $R \& D$. Bandung: Alfabeta.

Undang Sudarsana, N. W. (2018). Upaya Pustakawan Dalam Mengatasi Vandalisme. Journal of Information and Library Studies, 53. 